\title{
Health Factors Associated with Frailty Biomarkers in the Elderly
}

\author{
Jair S. Virtuoso-Junior ${ }^{1}$ (D) $\triangle$ Kelly C. P. Rosa ${ }^{2}$ (D), Renato M. Ribeiro ${ }^{3}$ (D) and Sheilla Tribess 4 (D) \\ ${ }^{1234}$ Research Center on Physical Activity, Health and Aging, Department of Sport Sciences, Institute of Health Sciences, Federal \\ University of Triangulo Mineiro, Uberaba, Minas Gerais 38025-180, Brazil \\ $\exists$ Corresponding Author: Jair S. Virtuoso-Junior, E-mail: jair.junior@uftm.edu.br
}

\section{ARTICLE INFORMATION}

Received: June 20, 2021

Accepted: July 23, 2021

Volume: 1

Issue: 1

Dol: $10.32996 /$ jmhs.2021.2.2.1

\section{KEYWORDS}

Health Factors; Frailty Biomarkers; organism; alterations; immune system

\section{ABSTRACT}

Background: Few studies associate adverse health factors with frailty defined by biomarkers. Aim: To evaluate the association of adverse health factors in elderly people (controlled by age group, gender, and activity) with the combined analysis of leukocytes and brain-derived neurotrophic factor (BDNF). Method: The study was a cross-sectional epidemiological investigation of an integral part of the ELSIU (Uberaba Elderly Health Study), consisting of a sample of 241 elderly people. The data collection involved physical performance tests, anthropometric measurements, and a questionnaire through individual interviews. Fragility was defined by the concomitant presence of BDNF serum levels $\leq 1888.42 \mathrm{mg} / \mathrm{dL}$ (first quartile) and a leukocyte count lower than $4,000 \mathrm{~mm}^{3}$ or higher than $9,290 \mathrm{~mm}^{3}$. For the data analysis, descriptive statistic procedures (frequency, mean) and Poisson regression were used, $p \leq 0.05$. Results: The prevalence of frailty was $8.7 \%$, and this condition was more prevalent in elderly individuals who were hospitalized in the last three months (RP $=7.33)$ and among those with disability in the basic activities of daily living (BADLs) $(R P=7.64)$, controlled by age group, gender and the level of physical activity. Conclusion: The early identification of frailty using biomarkers associated with health factors (hospitalization and disability in BADLs) may provide early intervention for these individuals.

\section{Introduction}

In the aging process, among the organs and systems of the organism that suffers alterations, the immune system is one of the most affected because cellular and molecular modifications occur (Torres, Lima, Miranda, \&Romano-Silva, 2011) that make immune functioning less efficient in elderly individuals (Tarazona, Solana Ouyang \& Pawelec, 2002) due to alterations in the functions of the body (Torres et. al., 2011; Tarazona et al., 2002).

Evidence suggests that changes in the immune system are related to frailty (Yao, Li \& Leng, 2011). With aging, the immune system can be affected by inadequate nutritional conditions, exaggerated levels of stress, disease, and other factors, compromising its functionality, as well as immunosenescence (Tonet \& Nobreba, 2008), which is a term used for the immune system dysfunctions observed in aging (Torres et al., 2011).

Frailty syndrome is marked by three alterations related to the aging process itself (senescence) that result from advancing age: neuromuscular changes (sarcopenia, osteopenia, and decreases in muscle fiber), the dysregulation of the neuroendocrine system (hypothalamus-pituitary axis), and the dysfunction of the immune system (inflammation and immunity) (Fried, Tangen, Walston, Newman, Hirsch, Gottdiener, Seeman, Tracy, Kop, Burke \& McBurnie, 2001; Walston \& Fried, 1999).

The dysregulation of the inflammatory response existing in the presence or absence of acute or chronic diseases can influence the health status of elderly individuals, making them more fragile and vulnerable to diseases, with a functional decline that may lead

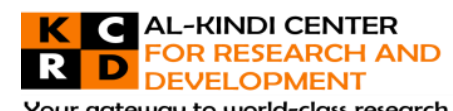

Your gateway to world-class research

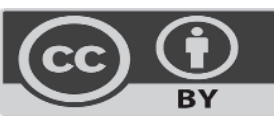

Published by Al-Kindi Center for Research and Development, United Kingdom. Copyright (c) the author(s). This open access article is distributed under a Creative Commons Attribution (CC-BY) 4.0 license 
to death. The hypothesis of a probable biological basis for frailty syndrome is based on this association (Ershler \& Keller, 2000; Leng, Chaves, Koening \& Walston, 2002; Rantanen, Volpato, Ferruci, Heikkinen, Fried \& Guralnilk, 2003; Walston, McBurnie, Newman, Tracy, Kop, Hirsch, Gottdiener \& Fried, 2002).

Despite evidence showing that inflammation plays an important role in the pathogenesis of frailty, it is important to consider the innate and adaptive immunity changes that may be related to inflammation and increased vulnerability to infections in fragile older people (Yao et al., 2011). There are several stimuli involved in the onset and progression of the inflammatory response, and caution is therefore required in choosing the inflammatory markers to be used in clinical practice (Pearson, Mensah, Alexander, Anderson, Cannon, Criqui, Fadl, Fortmann, Hong, Myers, Rifai, Smith Jr, Taubert, Tracy \& Vinicor, 2003) and in controlling some variables such as physical activity.

Among the biomarkers that have been gaining ground in the academic world to understand frailty, as they are more reliable and more accurate methods of obtaining results, we highlight interleukin-6 (Ershler \& Keller, 2000), C reactive protein (Walston et al., 2002), and leukocytes (Leng, Hung, Cappola, Yu, Xue \& Fried, 2009), as well as protein markers, along with serum levels of BDNF (brain-derived neurotrophic factor) (Inglés, Gambini, Mas-Bargues, García-García, Viña \& Borrás, 2017).

Evidence shows the association between high white cell count and frailty, suggesting that the immune system is more active in fragile elderly than in nonfragile elderly (Yao et al., 2011; Leng, Xue, Huang, Ferrucci, Fried \& Walston, 2005; Margolis, Manson, Greenland, Rodabough, Bray, Safford, Grimm, Howard, Assaf, Prentice \& Women's Health Initiative Research Group, 2005; Ruggiero, Metter, Cherubini, Maggio, Sen, Najjar, Windham, Ble, Senin \& Ferrucci, 2007). Additionally, lower BDNF levels have been observed in frail elderly than in both prefrail and non-frail elderly individuals (Inglés et al., 2017).

Since frailty is an important factor related to aging, the determination of adverse health outcomes, such as hospitalization, functional disability, falls, medication use, and death, as well as the association of these adverse factors with biochemical markers, is of great value to the community, enabling the proposition of more effective interventions in the prevention of frailty.

Thus, the objective of this study was to evaluate the association of adverse health factors in elderly individuals (controlled by age, sex, and physical activity) with the combined analysis of leukocytes and BDNF.

\section{Methods}

\subsection{Study and Population Characteristics}

This study was an observational, analytical and cross-sectional study using exploratory surveys, performance tests, and evaluation by blood biomarkers. This research is an integral part of an urban population-based epidemiological research study called ELSIU (Uberaba Elderly Health Study).

The municipality of Uberaba is located in the extreme south of the Minas Gerais, in the southeastern region of Brazil. Elderly residents of the urban area of Uberaba, MG, aged 60 years or older, who were registered in the Family Health Strategy (FHS) were eligible for inclusion in the study.

Methods pertaining to population and sample selection have been published elsewhere (Paulo, Tribess, Sasaki, Meneguci, Martins, Freitas, Romo-Perez \& Virtuoso, 2016). The study included elderly individuals who did not use a wheelchair, who did not have severe visual and hearing difficulties, who were not bedridden, who had no severe sequelae of stroke with localized loss of strength, and who did not have a terminal disease.

Of the 622 elderly people evaluated in the first study collection (2010), in 2018, 58 were excluded for not meeting the inclusion criteria, 158 were not found and 165 refused to provide a blood sample, resulting in a final sample of 241 subjects with 60 years or more.

Elderly individuals were excluded from the study when they had a score < 12 points on the Mini-Mental State Exam; were unable to walk, even with the aid of a cane or walker; had severe impairment in visual and hearing acuity, according to the interviewer's perception; had wheelchair dependence, or had severe sequelae of stroke with a localized loss of strength. 


\subsection{Data Collection Procedures}

The data collection team consisted of previously trained health professionals and academics. For this purpose, we contacted the Uberaba Municipal Health Secretariat and extensively communicated with the local community through social media. Data were collected using a battery of physical performance tests (upper limb strength and gait speed), anthropometric measurements (weight and height), and home and individual interview scripts composed of sociodemographic and behavioral information.

\subsection{Sociodemographic Information}

The information on the following items was collected: gender (male or female), age group (in years; 60 to 69 and $\geq 70$ years), marital status (single, married or living with a partner, widower or divorced), education (years of schooling; illiterate, 1 to 2 , $\geq 3$ years), and individual income minimum wages (no income, up to $2, \geq 3$ wages).

\subsubsection{Health Information}

Functional capacity was assessed by performing basic activities of daily living (BADLs) using the independence scale for BADLs, the Katz index, developed by Katz et al. (Katz, Ford, Moskowitz, Jackson \& Jaffe, 1963) and adapted to the Brazilian population (Lino, Pereira, Camacho, Ribeiro Filho \& Buksman, 2008). This index has six items that measure a person's performance in self-care activities (Katz et al., 1963).

Instrumental activities of daily living (IADLs) were also measured using the Lawton and Brody (Lawton \& Brody, 1969) scale adapted to the Brazilian population (Santos \& Virtuoso Junior, 2008). This scale has eight items that measure a person's performance in social activities.

An elderly individual was considered independent when they did not have difficulty performing any of the BADLs and, for the IADLs, when they had a score equal to or higher than 11 points (Virtuoso Junior, Martins, Roza, de Paulo, Ribeiro \& Tribess, 2015).

Drug consumption was assessed through a questionnaire extracted from the Brazilian Multidimensional Functional Assessment Questionnaire (BMFAQ), in which elderly individuals are asked about the number of drugs they regularly use, subsequently classified as $0-2$ and $\geq 3$ drugs used continuously.

The occurrence of hospitalization falls and mortality was evaluated according to the items discussed by the researchers.

\subsubsection{Behavioral Information}

The level of physical activity was assessed by the International Physical Activity Questionnaire (IPAQ), and the elderly individuals were classified into two groups: an insufficiently active group ( $<150$ minutes/week spent in moderate to vigorous physical activity) and a sufficiently active group ( $\geq 150$ minutes/week spent in moderate to vigorous physical activity).

\subsubsection{Fragility}

Frailty was measured by the level of inflammatory biomarkers. Two $4 \mathrm{~mL}$ blood tubes of blood were collected for laboratory tests in vacuum blood collection tubes with ethylenediamine tetraacetic acid (EDTA) anticoagulant for the measurement of serum BDNF levels and global leukocyte count.

Blood was collected by the vacuum collection system after a 30 -minute rest period during which the individual sat in a chair. With the arm resting on a support, a tourniquet was placed at approximately the midpoint of the humerus and then the collection site was sterilized with $70 \%$ alcohol-soaked cotton. With the help of a vacuum manifold needle adapter, a $25 \times 8 \mathrm{~mm}$ disposable needle was inserted into one of the veins of the anterior cubital fossa of the arm. The tubes were placed on ice and then centrifuged for $20 \mathrm{~min}$ at $3000 \mathrm{rpm}$ at $8{ }^{\circ} \mathrm{C}$.

The reference value for frailty was defined as a BDNF concentration $\leq 1888.42 \mathrm{mg} / \mathrm{dL}$ (first quartile) and a global white blood cell count $\leq 4,000 \mathrm{~mm}^{3}$ or $>9,290 \mathrm{~mm}^{3}$ (Bovill, Bild Heiss, Kuller, Lee, Rock \& Wahl, 1996).

Regarding this frailty index, frailty in elderly individuals was characterized as the presence of two altered results in the evaluated components (BDNF and leukocyte count). 


\subsubsection{BDNF Analysis}

Blood was separated and plasma in EDTA was stored at $-80{ }^{\circ} \mathrm{C}$ until further analysis. Duplicate BDNF levels were measured by enzyme-linked immunosorbent assay (ELISA) using the Emax ${ }^{\circledR}$ BDNF ImmunoAssay System (Promega, Madison, WI, USA) according to the manufacturer's instructions. Ninety-six-well plates were sensitized with overnight capture anti-BDNF antibodies. After the sensitization period, the plates were washed to block nonspecific binding, and the sensitized and blocked plates were then incubated with the samples along with IgY class anti-BDNF polyclonal antibodies; anti-IgY detection was performed according to the recommendations of the manufacturer. The reactions were revealed by the addition of tetramethylbenzidine (TMB) and were interrupted by the addition of $4 \mathrm{M} \mathrm{H}_{2} \mathrm{SO}_{4}$ (sulfuric acid), and the reading was performed in a spectrophotometer at 450 nm. The final concentration result was normalized by the dilution factor used for the assay. All samples and standards were measured in duplicate, and duplicate media were used for statistical analysis.

\subsubsection{Leukocyte analysis}

Leukocytes were counted using the Sysmex XE-2100 Hematology Analyzer (Roche Diagnostics, Curitiba, Brazil), which utilizes semiconductor laser fluorescent flow cytometry technology and hydrodynamic focusing that allows greater sensitivity to leukocyte populations.

\subsection{Data Analysis}

Data were doubly entered into Epidata software, version 3.1b, and statistical analyses were performed in Statistical Package for Social Sciences (SPSS), version 21.

Descriptive statistics procedures were used to identify the sample with frequency distribution (absolute and relative) and the prevalence of frailty.

To identify the associated adverse health factors (BADLs, IADLs, medications, hospitalizations, and falls) and frailty (BDNF and leukocytes), the adjusted prevalence ratios (PRs) were calculated using Poisson regression. Regression analysis was adjusted for sociodemographic (gender and age), behavioral (physical activity level), and adverse health factors. For the calculation of adjusted prevalence ratios, a significance level of $5 \%$ and a confidence interval $(\mathrm{Cl})$ of $95 \%$ were considered.

\subsection{Ethical Procedures}

This research follows the ethical principles present in Resolution No. 466/12 of the National Health Council. The protocols of this research were evaluated by the Research Ethics Committee of the Federal University of Triangulo Mineiro and approved by Opinion No. $1.256 .069 / 2015$.

\section{Results}

The study population consisted of 241 elderly individuals, of whom $8.7 \%(n=21)$ were fragile.

Table 1 represents the sample characterization, with sociodemographic, health, and behavioral data. Of the 241 elderly participants in this study, 61.8\% $(n=149)$ were women and $57.7 \%(n=139)$ were between 60 and 69 years old. The continuous use of medication was reported by $80.5 \%(n=194)$ of respondents, and the occurrence of falls in the last year was $30.3 \%(n=73)$. In addition, $3.7 \%(n=9)$ of the participants reported a history of hospitalization in the last three months.

Table 1: Distribution of sociodemographic, behavioral, and health indicators of elderly individuals in the municipality of Uberaba, Minas Gerais, Brazil.

\begin{tabular}{ll}
\hline Variables & $\%(\mathrm{n})$ \\
\hline Sex & \\
Female & $61.8(149)$ \\
Male & $38.2(92)$ \\
Age range & \\
60 to 69 years & $57.7(139)$ \\
70 to 79 years old & $27.4(66)$ \\
80 years or older & $14.9(36)$ \\
Medication use & $80.5(194)$ \\
Yes & $19.5 \%(47)$ \\
No &
\end{tabular}




\begin{tabular}{|c|c|}
\hline \multicolumn{2}{|l|}{ Falls in the last year } \\
\hline Yes & $30.3(73)$ \\
\hline No & $69.7(168)$ \\
\hline \multicolumn{2}{|c|}{ Hospitalization in the last 3 months } \\
\hline Yes & $3.7(9)$ \\
\hline No & $96.3(232)$ \\
\hline \multicolumn{2}{|l|}{ Physical activity level } \\
\hline$<150 \mathrm{~min} /$ week & $46.1(111)$ \\
\hline$\geq 150 \mathrm{~min} /$ week & $53.9(130)$ \\
\hline \multicolumn{2}{|c|}{ Basic activities of daily living } \\
\hline Dependent & $23.2(56)$ \\
\hline Independent & $76.8(185)$ \\
\hline \multicolumn{2}{|c|}{ Instrumental activities of daily living } \\
\hline Dependent & $28.2(68)$ \\
\hline Independent & $71.8(173)$ \\
\hline
\end{tabular}

In the behavioral analysis, the level of physical activity was verified, and $46.1 \%(n=111)$ of the elderly individuals reported participating in less than 150 minutes/week of moderate and/or vigorous physical activity.

Elderly individuals who were dependent on assistance for BADLs represented $23.2 \%(n=56)$ of the total sample, and for IADLs, $28.2 \%(n=68)$ of the sample was dependent on assistance.

Table 2 shows the association between frailty and adverse health factors. There was an association between frailty and a history of hospitalizations in the last 3 months $(P R=7.33)$ and basic activities of daily living $(P R=7.64)$.

Table 2: Association of frailty with adverse health factors in elderly individuals of Uberaba, Minas Gerais, Brazil.

\begin{tabular}{|c|c|c|c|c|}
\hline Variables & Wald $\chi^{2}$ & PR & $95 \% \mathrm{Cl}$ & $\mathrm{p}$ \\
\hline Medication use & 0.98 & & & 0.322 \\
\hline No & & 1 & & \\
\hline Yes & & 2.89 & $0.35-23.62$ & \\
\hline Occurrence of falls & 0.51 & & & 0.477 \\
\hline No & & 1 & & \\
\hline Yes & & 1.34 & $0.60-3.00$ & \\
\hline Hospitalization last 3 months & 7.33 & & & 0.007 \\
\hline No & & 1 & & \\
\hline Yes & & 4.22 & $1.49-11.97$ & \\
\hline Basic activities of daily living & 7.64 & & & 0.006 \\
\hline Independent & & 1 & & \\
\hline Dependent & & 3.40 & $1.43-8.08$ & \\
\hline Instrumental activities of daily living & 0.06 & & & 0.813 \\
\hline Independent & & 1 & & \\
\hline Dependent & & 0.91 & $0.42-1.98$ & \\
\hline
\end{tabular}

* Adjusted by gender, age group, and physical activity level.

\section{Discussion}

This research is part of the Uberaba Elderly Health Study (ELSIU). This is the first home-based epidemiological study conducted with Brazilian elderly individuals of both sexes, providing information on the fragility established by changes in BDNF and leukocyte levels associated with adverse health factors (falls, hospitalizations, drug use, and functional disability). The results show that frailty is more frequent among elderly individuals with hospitalization in the last three months and among those with an inability to perform the basic activities of daily living. 
Frailty is a broad and dynamic concept and is related to the decrease in function of multiple systems, causing a state of more significant vulnerability with a propensity to adverse health factors such as dependence, falls, drug use, and hospitalization (Fried, Ferrucci, Darer, Williamson \& Anderson, 2004). In the diagnosis of fragility, the warning signs supported by the phenotypes are commonly used in clinical practice; however, studies involving biomarkers have been gaining ground for understanding frailty (Walston et al., 2002, Leng et al., 2009).

In the present investigation, the prevalence of frailty was lower than that of other population studies in the country; however, most of these studies were performed using the frailty phenotype as a reference in the classification of frail elderly (Carneiro, Cardoso, Durães, Guedes, Santos, Costa \& Caldeira, 2017; Cruz, Vieira, Bastos \& Leite, 2017; Tavares, Faria, Pegorari, Ferreira, Nascimento \& Marchiori, 2018). The determination of frailty from two biomarkers imposes, to a certain extent, greater precision for the evaluated attribute, either in the immunological marker (leukocyte count) or in cell survival and differentiation (BDNF levels). However, the high number of refusals to provide blood samples may have interfered with this result as, in general, the most fragile elderly individuals are more reactive to evaluations.

Regardless of the limitations of the study imposed by the reactivity to blood collection, the results of this study indicate with a certain precision the most prevalent adverse health factors in the condition of frailty.

The prevalence of frailty was approximately 4 times more prevalent among those who reported hospitalization in the last three months and approximately 3 times more prevalent for those who reported inability to perform basic activities of daily living.

Regarding the greater hospitalization rate of elderly individuals, the results of this study agree with those of studies that verify frailty through phenotypes (Vieira, Guerra, Giacomin, Vasconcelos, Andrade, Pereira, Dias \& Dias, 2013), showing that the use of biomarkers is capable of detecting adverse health events.

Many of these events can be attributed to inadequate discharge schedules that lack information and out-of-hospital health-related follow-up for individuals. Investment in health care resources, especially posthospitalization services, is increasingly needed (Covinsky, Palmer, Fortinsky, Counsell, Stewart, Kresevic, Burant \& Landefeld, 2003; Podrazik \& Whelan, 2008). There are some models of care that can be provided for frail older people, such as Geriatric Evaluation and Management (GEM), Comprehensive Geriatric Assessment (CGA), the Program for All-Inclusive Care of Elderly (PACE; an integral care program for elderly individuals) and Acute Care for Elderly (ACE). These programs aim to provide care to elderly individuals in an interdisciplinary manner, providing a better opportunity for health recovery in their homes to avoid readmission (Counsell, Holder, Liebenauer, Palmer, Fortinsky, Kresevic, Quinn, Allen, Covinsky \& Landefeld, 2000; Espinoza \& Walston, 2005).

Thus, planning the discharge of frail elderly individuals is necessary so that they do not return to the hospital in a short time. This planning should include family members, caregivers, primary care health professionals, and specialists (Podrazik et al., 2008).

Regarding the BADLs, the results of this study corroborate those of the study by Salvi et al. (Salvi, Morichi, Grilli, Lancioni, Spazzafumo, Polonara, Abbatecola, De Tommaso, Dessi-Fulgheri \& Lattanzio, 2012), who investigated elderly individuals in Italy and found that the frail individuals had a greater chance of functional decline in the BADLs than the nonfragile individuals at the 180-day follow-up after hospital discharge, as in the Mexican elderly survey; however, these elderly individuals were followed up over 2 years (Díaz, Tamez, Gutiérrez, Cedillo \& Torres, 2012).

Hierarchically, losses occur from the IADLs to the BADLs (dos Santos \& Pavarini, 2012) because IADLs require greater physical and cognitive integrity than BADLs (Freitas, Fernandes, Coqueiro, Reis Júnior, Rocha \& Brito, 2012; Millán-Calenti, Tubío, Pita-Fernández, González-Abraldes, Lorenzo, Fernández-Arruty \& Maseda, 2010). The relationship between disability and frailty is first evidenced in IADLs (Tapia-Arancibia, Aliaga, Silhol \& Arancibia, 2008), and impairment in these contributes to greater distancing from the social environment and a tendency toward isolation. BADLs are associated with survival (Rodrigues, Pedrazzi, \& Schiaveto, 2007).

The relationship factor found in the present study was only in the BADLs, which reflects the level of vulnerability of the elderly individuals classified as fragile, since the prevalence of frailty, found to be $8.7 \%$, may reflect those elderly individuals with a more aggravated fragile condition in the BADLs.

The importance of health monitoring in the postdischarge period, especially in the first three months, to avoid or postpone disabilities is emphasized here, because if there are no short-term interventions, limitations may evolve until the elderly individual becomes dependent on assistance with activities for life maintenance. 
Frailty may predict disability, and disability may aggravate fragility, but they are entities with different prognoses that require specific prevention and intervention measures (Fried et al., 2001).

Most factors related to the decreased functional capacity of hospitalized elderly individuals can be predicted and are subject to intervention. The implementation of units specifically designed for the care of elderly individuals, interdisciplinary work, continuous assessments, the rational use of medicines, and the planning of appropriate therapies may favor a reduction in the incidence of functional decline, with a favorable impact on the quality of life (Zelada, Salinas \& Baztán, 2009). Hospitalization, rather than illness, is often the leading cause of the functional decline in elderly individuals (Covinsky et al., 2003).

\section{Conclusions}

The identification of robust biomarkers for the assessment of the condition of the greater vulnerability of the elderly to adverse events makes it possible to expand the alternatives for early diagnosis of the population in health services, therefore, it is still necessary to carry out further studies to identify new biomarkers, as well as the reference criteria of these biomarkers for the decision-making action by health professionals to be more assertive.

Based on the results presented, the prevalence of frailty was $8.7 \%$, and there was a high proportion of frail elderly individuals hospitalized in the last three months and those with disabilities in the basic activities of daily living.

This study reinforces the importance of assessing the presence of frailty in elderly individuals by analyzing inflammatory and neurotrophic markers. The early identification of frailty with the use of leukocyte count and BDNF can provide timely intervention to prevent the emergence of diseases associated with frailty in elderly individuals, as well as actions to control the associated risk factors.

The results of this investigation are important because they generate knowledge for the direction, improvement, and planning of interventions to prevent the deterioration of the health of elderly individuals. Frail elderly individuals should receive quality care to avoid the aggravation of adverse health factors and the evolution of the preliminary stages to advanced frailty.

Data Availability: Data can be made available upon reasonable request.

Conflicts of Interest: The authors declare that they have no conflicts of interest.

Funding Statement: This work was supported by the Minas Gerais Research Funding Foundation (Fapemig) - Notice 02/2015 Universal Demand, grant number: CDS-APQ-00592-15.

\section{References}

[1] Bovill, E. G., Bild, D. E., Heiss, G., Kuller, L. H., Lee, M. H., Rock, R., \& Wahl, P. W. (1996). White blood cell counts in persons aged 65 years or more from the Cardiovascular Health Study. Correlations with baseline clinical and demographic characteristics. American journal of epidemiology, 143(11), 1107-1115. https://doi.org/10.1093/oxfordjournals.aje.a008687

[2] Carneiro, J. A., Cardoso, R. R., Durães, M. S., Guedes, M., Santos, F. L., Costa, F., \& Caldeira, A. P. (2017). Frailty in the elderly: prevalence and associated factors. Revista brasileira de enfermagem, 70(4), 747-752. https://doi.org/10.1590/0034-7167-2016-0633

[3] Cruz, D., Vieira, M. T., Bastos, R. R., \& Leite, I. (2017). Factors associated with frailty in a community-dwelling population of older adults. Revista de saude publica, 51, 106. https://doi.org/10.11606/S1518-8787.2017051007098

[4] Counsell, S. R., Holder, C. M., Liebenauer, L. L., Palmer, R. M., Fortinsky, R. H., Kresevic, D. M., Quinn, L. M., Allen, K. R., Covinsky, K. E., \& Landefeld, C. S. (2000). Effects of a multicomponent intervention on functional outcomes and process of care in hospitalized older patients: a randomized controlled trial of Acute Care for Elders (ACE) in a community hospital. Journal of the American Geriatrics Society, 48(12), 1572-1581. https://doi.org/10.1111/j.1532-5415.2000.tb03866.x

[5] Covinsky, K. E., Palmer, R. M., Fortinsky, R. H., Counsell, S. R., Stewart, A. L., Kresevic, D., Burant, C. J., \& Landefeld, C. S. (2003). Loss of independence in activities of daily living in older adults hospitalized with medical illnesses: increased vulnerability with age. Journal of the American Geriatrics Society, 51(4), 451-458. https://doi.org/10.1046/j.1532-5415.2003.51152.x

[6] Díaz de León González, E., Tamez Pérez, H. E., Gutiérrez Hermosillo, H., Cedillo Rodríguez, J. A., \& Torres, G. (2012). Fragilidad y su asociación con mortalidad, hospitalizaciones y dependencia funcional en mexicanos de 60 años o más [Frailty and its association with mortality, hospitalization and functional dependence in Mexicans aged 60-years or older]. Medicina clinica, 138(11), 468-474. https://doi.org/10.1016/j.medcli.2011.03.024

[7] Dos Santos, A. A., \& Pavarini, S. C. (2012). Funcionalidade familiar de idosos com alterações cognitivas: a percepção do cuidador [Family functionality regarding the elderly with cognitive impairments: the caretaker's perception]. Revista da Escola de Enfermagem da U S P, 46(5), 1141-1147. https://doi.org/10.1590/s0080-62342012000500015

[8] Ershler, W. B., \& Keller, E. T. (2000). Age-associated increased interleukin-6 gene expression, late-life diseases, and frailty. Annual Review of Medicine, 51:245-70. doi: 10.1146/annurev.med.51.1.245. 
[9] Espinoza, S., \& Walston, J. D. (2005). Frailty in older adults: insights and interventions. Cleveland Clinic journal of medicine, 72(12), 11051112. https://doi.org/10.3949/ccjm.72.12.1105

[10] Inglés, M., Gambini, J., Mas-Bargues, C., García-García, F. J., Viña, J., \& Borrás, C. (2017). Brain-derived neurotrophic factor as a marker of cognitive frailty. The Journals of Gerontology. Series A, Biological Sciences and Medical Sciences, 72(3):450-451. doi: 10.1093/gerona/glw145. Inglés, M., Gambini, J., Mas-Bargues, C., García-García, F. J., Viña, J., \& Borrás, C. (2017). Brain-derived neurotrophic factor as a marker of cognitive frailty. The Journals of Gerontology. Series A, Biological Sciences and Medical Sciences, 72(3):450-451. doi: 10.1093/gerona/glw145.

[11] Freitas, R. S., Fernandes, M. H., Coqueiro, R. S., Reis Júnior, W. M., Rocha, S. V., \& Brito, R. T. A. (2012). Functional capacity and associated factors in the elderly: a population study. Acta Paulista de Enfermagem, 25(6):933-939. https://doi.org/10.1590/S0103-21002012000600017

[12] Fried, L. P., Ferrucci, L., Darer, J., Williamson, J. D., \& Anderson, G. (2004). Untangling the concepts of disability, frailty, and comorbidity: implications for improved targeting and care. The journals of gerontology. Series A, Biological sciences and medical sciences, 59(3), 255263. https://doi.org/10.1093/gerona/59.3.m255

[13] Fried, L. P., Tangen, C. M., Walston, J., Newman, A. B., Hirsch, C., Gottdiener, J., Seeman, T., Tracy, R., Kop, W. J., Burke, G., \& McBurnie, M. A. (2001). Frailty in older adults: evidence for a phenotype. The Journals of Gerontology. Series A, Biological Sciences and Medical Sciences, 56(3): M146-56. doi: 10.1093/gerona/56.3.m146.

[14] Katz, S., Ford, A. B., Moskowitz, R. W., Jackson, B. A., \& Jaffe, M. W. (1963). Studies of illness in the aged. The index of adl: a standardized measure of biological and psychosocial function. JAMA, 185, 914-919. https://doi.org/10.1001/jama.1963.03060120024016

[15] Krabbe, K. S., Pedersen, M., \& Bruungaard, H. (2004). Inflammatory mediators in the elderly. Experimental Gerontology, 39(5):687-99. doi: 10.1016/j.exger.2004.01.009.

[16] Lawton, M. P., \& Brody, E. M. (1969). Assessment of older people: self-maintaining and instrumental activities of daily living. The Gerontologist, 9(3), 179-186.

[17] Leng, S., Chaves, P., Koenig, K., \& Walston, J. (2002). Serum interleukin- 6 and hemoglobin as physiological correlates in the geriatric syndrome of frailty: a pilot study. Journal of the American Geriatrics Society, 50(7):1268-71. doi: 10.1046/j.1532-5415.2002.50315.x.

[18] Leng, S. X., Hung, W., Cappola, A. R., Yu, Q., Xue, Q. L., \& Fried, L. P. (2009). White blood cell counts, insulin-like growth factor-1 levels, and frailty in community-dwelling older women. The Journals of Gerontology. Series A, Biological Sciences and Medical Sciences, 64(4):499-502. doi: 10.1093/gerona/gln047.

[19] Leng, S.X., Xue, Q.L., Huang, Y., Ferrucci, L., Fried, L.P., \& Walston, J.D. (2005). Baseline total and specific differential white blood cell counts and 5-year all-cause mortality in community-dwelling older women. Experimental Gerontology, 40(12):982-7. doi: 10.1016/j.exger.2005.08.006. Epub 2005 Sep 23. PMID: 16183235.

[20] Lino, V. T., Pereira, S. R., Camacho, L. A., Ribeiro Filho, S. T., \& Buksman, S. (2008). Adaptação transcultural da Escala de Independência em Atividades da Vida Diária (Escala de Katz) [Cross-cultural adaptation of the Independence in Activities of Daily Living Index (Katz Index)]. Cadernos de saude publica, 24(1), 103-112. https://doi.org/10.1590/s0102-311x2008000100010

[21] Margolis, K. L., Manson, J. E., Greenland, P., Rodabough, R. J., Bray, P. F., Safford, M., Grimm, R. H., Jr, Howard, B. V., Assaf, A. R., Prentice, R., \& Women's Health Initiative Research Group (2005). Leukocyte count as a predictor of cardiovascular events and mortality in postmenopausal women: the Women's Health Initiative Observational Study. Archives of internal medicine, 165(5), 500-508. https://doi.org/10.1001/archinte.165.5.500

[22] Millán-Calenti, J. C., Tubío, J., Pita-Fernández, S., González-Abraldes, I., Lorenzo, T., Fernández-Arruty, T., \& Maseda, A. (2010). Prevalence of functional disability in activities of daily living (ADL), instrumental activities of daily living (IADL) and associated factors, as predictors of morbidity and mortality. Archives of gerontology and geriatrics, 50(3), 306-310. https://doi.org/10.1016/j.archger.2009.04.017

[23] Paulo T, R. S., Tribess, S., Sasaki, J. E., Meneguci, J., Martins, C. A., Freitas, I. F., Jr, Romo-Perez, V., \& Virtuoso, J. S., Jr (2016). A Cross-Sectional Study of the Relationship of Physical Activity with Depression and Cognitive Deficit in Older Adults. Journal of aging and physical activity, 24(2), 311-321. https://doi.org/10.1123/japa.2014-0253

[24] Pearson, T. A., Mensah, G. A., Alexander, R. W., Anderson, J. L., Cannon, R. O., Criqui, M., Fadl, Y. Y., Fortmann, S. P., Hong, Y., Myers, G. L., Rifai, N., Smith Jr, S. C., Taubert, K., Tracy, R. P., \& Vinicor, F. (2003). Markers of inflammation and cardiovascular disease: application to clinical and public health practice: a statement for healthcare professionals from the centers for disease control and prevention and the American heart association. Circulation, 28;107(3):499-511. doi: 10.1161/01.cir.0000052939.59093.45.

[25] Podrazik, P. M., \& Whelan, C. T. (2008). Acute hospital care for the elderly patient: its impact on clinical and hospital systems of care. The Medical clinics of North America, 92(2), 387-ix. https://doi.org/10.1016/j.mcna.2007.11.004

[26] Rantanen, T., Volpato, S., Ferrucci, L., Heikkinen, E., Fried, L. P., \& Guralnik, J. M. (2003). Handgrip strength and cause-specific and total mortality in older disabled women: exploring the mechanism. Journal of the American Geriatrics Society, 51(5):636-41. doi: 10.1034/j.16000579.2003.00207.x.

[27] Rodrigues, R. A. P., Pedrazzi, E. C., \& Schiaveto, F. V. (2007). Referred morbidity and functional capacity of the elderly. Ciência, Cuidado e Saúde, 6(4):407-413. https://doi.org/10.4025/cienccuidsaude.v6i4.3391

[28] Ruggiero, C., Metter, E. J., Cherubini, A., Maggio, M., Sen, R., Najjar, S. S., Windham, G. B., Ble, A., Senin, U., \& Ferrucci, L. (2007). White blood cell count and mortality in the Baltimore Longitudinal Study of Aging. Journal of the American College of Cardiology, 49(18), 1841-1850. https://doi.org/10.1016/j.jacc.2007.01.076

[29] Santos, R. L., \& Virtuoso Junior, J. (2008). Reliability of the Brazilian version of the Scale of Instrumental Activities of Daily Living. Revista Brasileira em Promoção da Saúde, 21(4):290-296.

[30] Salvi, F., Morichi, V., Grilli, A., Lancioni, L., Spazzafumo, L., Polonara, S., Abbatecola, A. M., De Tommaso, G., Dessi-Fulgheri, P., \& Lattanzio, F. (2012). Screening for frailty in elderly emergency department patients by using the Identification of Seniors At Risk (ISAR). The journal of nutrition, health \& aging, 16(4), 313-318. https://doi.org/10.1007/s12603-011-0155-9

[31] Tapia-Arancibia, L., Aliaga, E., Silhol, M., \& Arancibia, S. (2008). New insights into brain BDNF function in normal aging and Alzheimer disease. Brain research reviews, 59(1), 201-220. https://doi.org/10.1016/j.brainresrev.2008.07.007 
[32] Tarazona, R., Solana, R., Ouyang Q., \& Pawelec, G. (2002). Basic biology and clinical impact of Experimental Gerontology, 37(2-3):183-9. doi: 10immunosenescence..1016/s0531-5565(01)00182-6.

[33] Tavares, D., Faria, P. M., Pegorari, M. S., Ferreira, P., Nascimento, J. S., \& Marchiori, G. F. (2018). Frailty Syndrome in Association with Depressive Symptoms and Functional Disability among Hospitalized Elderly. Issues in mental health nursing, 39(5), 433-438. https://doi.org/10.1080/01612840.2018.1429035

[34] Tonet, A. C.; \& Nobrega, O. T. (2008). Immunosenescence: the association between leukocytes, cytokines and chronic diseases. Revista Brasileira de Geriatria e Gerontologia, 11(2):259-273. https://doi.org/10.1590/1809-9823.2008.110210

[35] Torres, K. C., Lima G. S. F., Miranda, D. M., \& Romano-Silva, M. A. (2011). Immunosenescence. Geriatria \& Gerontologia, 5(3):163-169.

[36] Vieira, R. A., Guerra, R. O., Giacomin, K. C., Vasconcelos, K. S., Andrade, A. C., Pereira, L. S., Dias, J. M., \& Dias, R. C. (2013). Prevalência de fragilidade e fatores associados em idosos comunitários de Belo Horizonte, Minas Gerais, Brasil: dados do estudo FIBRA [Prevalence of frailty and associated factors in community-dwelling elderly in Belo Horizonte, Minas Gerais State, Brazil: data from the FIBRA study]. Cadernos de saude publica, 29(8), 1631-1643. https://doi.org/10.1590/0102-311x00126312

[37] Virtuoso Junior, J. S., Martins, C. A., Roza, L. B., de Paulo, T. R. S., Ribeiro, M. C. L., \& Tribess, S. (2015). Prevalence of disability and associated factors in the elderly. Texto \& Contexto Enfermagem, 24(2):521-529, https://doi.org/10.1590/0104-07072015001652014

[38] Walston, J., McBurnie, M. A., Newman, A., Tracy, R. P., Kop, W., Hirsch, C. H., Gottdiener, J., \& Fried, L. P. (2002). Frailty and activation of the inflammation and coagulation systems with and without clinical comorbidities: results from the Cardiovascular Health Study. Archives of Internal Medicine, 11;162(20):2333-41. doi: 10.1001/archinte.162.20.2333.

[39] Walston, J., \& Fried, L. P. (1999). Frailty and the older man. The Medical clinics of North America, 83(5), 1173-1194. https://doi.org/10.1016/s0025-7125(05)70157-7

[40] Yao, X., Li, H., \& Leng S. X. (2011). Inflammation and immune system alterations in frailty. Clinics in Geriatric Medicine, 27(1):79-87. doi: 10.1016/j.cger.2010.08.002

[41] Zelada, M. A., Salinas, R., \& Baztán, J. J. (2009). Reduction of functional deterioration during hospitalization in an acute geriatric unit. Archives of gerontology and geriatrics, 48(1), 35-39. https://doi.org/10.1016/j.archger.2007.09.008 